\title{
Influence of surface morphology on the immersion mode ice nucleation efficiency of hematite particles
}

\author{
N. Hiranuma ${ }^{1}$, N. Hoffmann ${ }^{1}$, A. Kiselev ${ }^{1}$, A. Dreyer ${ }^{2,}{ }^{*}$, K. Zhang ${ }^{3}$, G. Kulkarni ${ }^{3}$, T. Koop ${ }^{2}$, and O. Möhler ${ }^{1}$ \\ ${ }^{1}$ Institute for Meteorology and Climate Research - Atmospheric Aerosol Research, Karlsruhe Institute of Technology, \\ Karlsruhe, Germany \\ ${ }^{2}$ Faculty of Chemistry, Bielefeld University, Bielefeld, Germany \\ ${ }^{3}$ Atmospheric Science and Global Change Division, Pacific Northwest National Laboratory, Richland, Washington, USA \\ * now at: Institute Advanced Ceramics, Hamburg University of Technology, Hamburg, Germany
}

Correspondence to: N. Hiranuma (seong.moon@kit.edu)

Received: 13 August 2013 - Published in Atmos. Chem. Phys. Discuss.: 10 September 2013

Revised: 21 January 2014 - Accepted: 30 January 2014 - Published: 5 March 2014

\begin{abstract}
In this paper, the effect of the morphological modification of aerosol particles with respect to heterogeneous ice nucleation is comprehensively investigated for laboratorygenerated hematite particles as a model substrate for atmospheric dust particles. The surface-area-scaled ice nucleation efficiencies of monodisperse cubic hematite particles and milled hematite particles were measured with a series of expansion cooling experiments using the Aerosol Interaction and Dynamics in the Atmosphere (AIDA) cloud simulation chamber. Complementary offline characterization of physico-chemical properties of both hematite subsets were also carried out with scanning electron microscopy (SEM), energy dispersive X-ray (EDX) spectroscopy, dynamic light scattering (DLS), and an electro-kinetic particle charge detector to further constrain droplet-freezing measurements of hematite particles. Additionally, an empirical parameterization derived from our laboratory measurements was implemented in the single-column version of the Community Atmospheric Model version 5 (CAM5) to investigate the model sensitivity in simulated ice crystal number concentration on different ice nucleation efficiencies. From an experimental perspective, our results show that the immersion mode ice nucleation efficiency of milled hematite particles is almost an order of magnitude higher at $-35.2^{\circ} \mathrm{C}<T<-33.5^{\circ} \mathrm{C}$ than that of the cubic hematite particles, indicating a substantial effect of morphological irregularities on immersion mode freezing. Our modeling results similarly show that the increased droplet-freezing rates of milled hematite particles lead to about one order magnitude higher ice crystal num-
\end{abstract}

ber in the upper troposphere than cubic hematite particles. Overall, our results suggest that the surface irregularities and associated active sites lead to greater ice activation through droplet freezing.

\section{Introduction}

The chemical and physical surface structure of an aerosol particle can greatly influence its microphysical characteristics such as hygroscopicity (e.g., Twohy and Anderson, 2008; Shilling et al., 2007), chemical reactivity (e.g., Di Cosimo et al., 1998), optical properties (Linke et al., 2006), and ice nucleation efficiency (e.g., Schill and Tolbert, 2013; Chapter 9 of Pruppacher and Klett, 1997). More specifically on ice nucleation properties, Möhler et al. (2006) and Kulkarni and Dobbie (2010) postulated that surface roughness and irregularities may lead to an enhancement of ice nucleation rate of dust particles by water vapor deposition on dust surface. It has been known that surfaces that show a structural match to the crystal lattice of hexagonal ice (e.g., AgI with $\mathrm{NH}_{4} \mathrm{I}$ ) may facilitate nonpolar proton-disordered ice propagation and ice formation (Jacquemain et al., 1991). It has been also discussed that the surface's physical and chemical properties may play a major role in the initiation of ice crystals in mixed-phase clouds and ice clouds (Mason, 1971; Cziczo et al., 2013), yet our current understanding of ice nucleation properties of various aerosols is still rudimentary, in part due to the fact that changes in composition, size, and 
surface morphology are often inherently related during an aerosol's atmospheric lifetime and aging process (Hiranuma et al., 2013).

Previous laboratory studies have revealed that electric fields promote the formation of ice-like aggregates and eventually induce ice nucleation (Ehre et al., 2010; Anim-Danso et al., 2013; Gavish et al., 1992). For instance, upon cooling water freezes preferentially on positively charged pyroelectric surfaces due to the prevalent interaction between lone electron pairs of water's oxygen atoms and the charged surface (Ehre et al., 2010). In contrast, negatively charged surfaces may coincide with a disrupted ice-like structural match, resulting in deteriorated freezing activity (Anim-Danso et al., 2013). In addition, Gavish et al. (1992) observed that artificially polarized crevices on hydrophobic surfaces induce an orientation of water molecules into ice-like clusters at a higher temperature than nonpolar crevices.

The importance of surface structure and irregularities towards ice nucleation were recently investigated by Croteau et al. (2010). The authors performed molecular dynamic simulations to investigate water adsorption on an irregularly shaped clay mineral surface, which includes a series of narrowly spaced trench-like defects. The results indicated that strong water affinity and apparent multilayers of water at the edges of these trenches where ice onset may preferentially occur may be due to the interaction between water and clay lattice compared to flat surface. These simulations help to understand the surface structures that may assist in ice nucleation; however, systematic laboratory studies performed under controlled conditions that can be used to further constrain and verify these molecular simulations are missing. In conjunction with aerosol-cloud interactions, ice nucleation enhancement in the presence of abundant water vapor would lead to more but smaller ice crystals, exerting higher albedo (Lohmann and Feichter, 2005). Hence, a surface morphology-dependent parameterization that accurately describes experimental results may be important to improve our climate change models.

In this study, we took an integrated approach that consists of experimental and cloud modeling investigations, to determine ice nucleation properties on hematite particles, with and without the presence of surface irregularities. We assumed hematite particles as surrogate for the natural mineral dust particles. Surface-area-scaled ice nucleation activities of different types of hematite particles were determined experimentally at atmospherically relevant conditions using the Aerosol Interaction and Dynamics in the Atmosphere (AIDA) cloud chamber. The degree of morphological irregularities, both in terms of size and surface charge, was assessed by in situ light scattering instruments as well as offline microscopy and spectroscopy techniques. In addition, a modeling sensitivity evaluation was performed with the simplified one-column version of the Community Atmospheric Model version 5, CAM5 (Neale et al., 2010), which allowed assessing the role of surface modification upon the overall ice

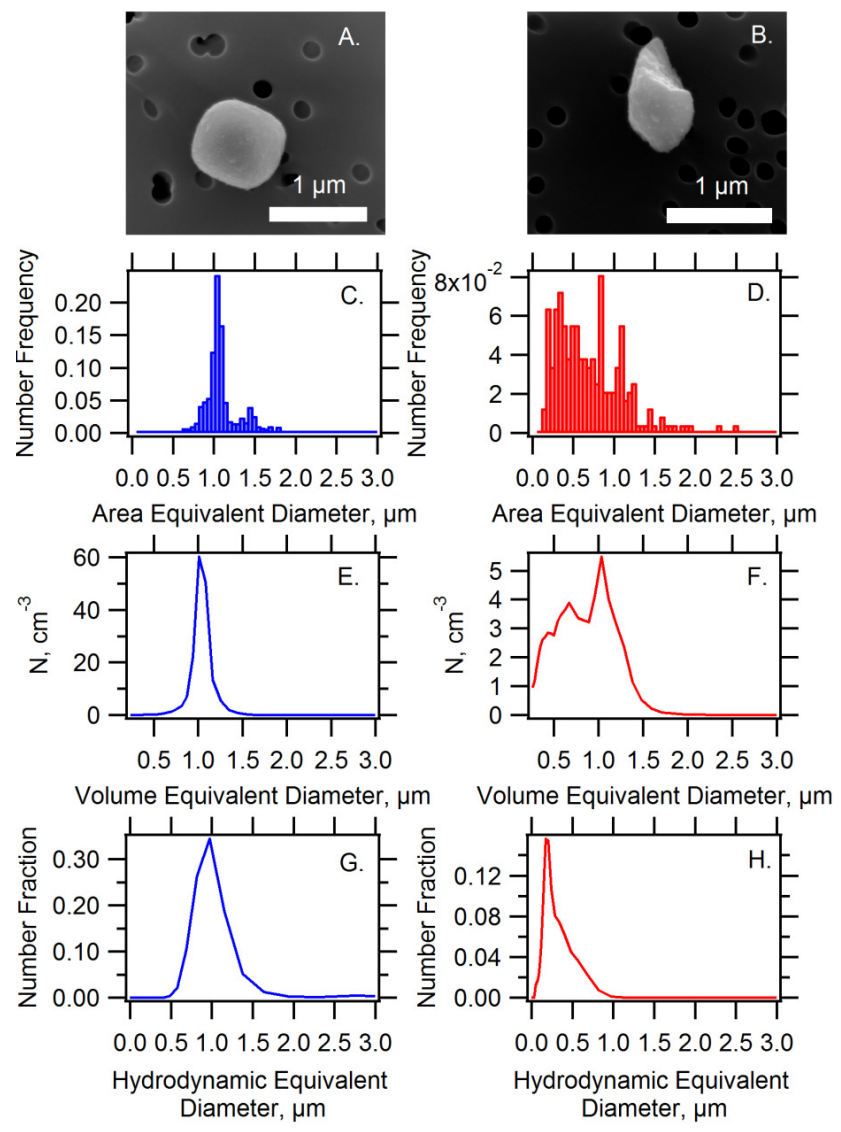

Fig. 1. SEM images of (A) a cubic hematite particle and (B) a milled hematite particle. Number frequencies estimated by SEM for each subset of hematite particles are shown in (C) and (D). Particle size distributions measured in the AIDA chamber are shown in (E) and (F). DLS measured size distributions are also shown in $(\mathbf{G})$ and $(\mathbf{H})$.

nucleation efficiency of the dust proxy in upper tropospheric ice clouds.

\section{Method}

\subsection{Sample preparation}

Chemically homogeneous cubic hematite $\left(\mathrm{Fe}_{2} \mathrm{O}_{3}\right)$ particles were produced following the procedure prescribed in Sugimoto and Sakata (1992). Briefly, iron hydroxide, $\mathrm{Fe}(\mathrm{OH})_{3}$ was initially produced by agitating a mixture of sodium hydroxide $(\mathrm{NaOH})$ and ferric chloride $\left(\mathrm{FeCl}_{3}\right)$ solutions (100 mL of $5.6 \mathrm{M}$ and $100 \mathrm{~mL}$ of $2.0 \mathrm{M}$, respectively). The resulting highly viscous gel form of $\mathrm{Fe}(\mathrm{OH})_{3}$ with an excess of $\mathrm{Fe}^{+3}$ was subsequently aged and freeze-dried to form a powder of equally sized hematite particles $(\sim 1 \mu \mathrm{m}$ diameter, see Fig. 1a). Next, a subset of these original cubic hematite particles was milled by agitating them with immiscible $100 \mu \mathrm{m}$ diameter bronze beads, resulting in surface irregularities (cracks and/or edges, see Fig. 1b). 
To assess the effect of surface milling, we used the Brunauer, Emmett and Teller (BET) $\mathrm{N}_{2}$-absorption technique (Brunauer et al., 1938) and measured the bulk surface area per given mass (i.e., specific surface area, $S_{\mathrm{BET}}, \mathrm{m}^{2} \mathrm{~g}^{-1}$ ) of both cubic and milled hematite particles. The BET technique reflects the most direct measurement of bulk surface area that is analogous to the ratio of surface area per given mass. A higher specific surface area of the milled hematite particles is indicative of the freshly introduced surfaces and presumably also localized features (e.g., edges). Additionally, surface charge properties and dynamic light scattering size of suspended hematite particles $(1-10 \mathrm{mg}$ hematite in $1 \mathrm{~mL}$ of triple-distilled water) were investigated using a StabiSizer ${ }^{\circledR}$ instrument (Microtrac Europe GmbH, PMX 200CS) to examine a possible relation between surface morphology and charge properties. The StabiSizer ${ }^{\circledR}$ has been widely used for many applications in particle analysis (e.g., Gaware et al., 2013; Titze et al., 2010). The detailed methods and its applications are described elsewhere for studying particle size using dynamic light scattering (DLS, Ukhatskaya et al., 2013) and surface charge properties as an electro-kinetic particle charge detector (Biver and Shotyk, 2013), so only a brief description will be given here. The hydrodynamic diameter of hematite particles was measured at a scattering angle of $180^{\circ}$ at a temperature of $25^{\circ} \mathrm{C}$. A $750 \mathrm{~nm}$ laser beam was focused onto a $10 \mathrm{mg} \mathrm{mL}^{-1}$ hematite suspension through a sapphire window, and the scattered light intensity was recorded and directly related to colloidal size distribution from the intensity fluctuations induced by the particles' Brownian motion. The particles' interfacial potential was electro-kinetically characterized by charge-pH titration based on the creation or extinction of surface charges (i.e., Brønsted-Lowry acidbase reaction) by incrementally adding $0.01 \mathrm{M}$ aqueous $\mathrm{HCl}$ or $\mathrm{NaOH}$ solutions to the hematite suspension. The measurement of the charge properties is based on the particle adsorption to the PTFE (polytetrafluoroethylene)-Teflon vessel wall. A swaying piston in the vessel creates an alternating solvent stream over these immobilized particles that deforms their flexible space-charge cloud and generates oscillating dipoles. These dipoles are detected as an oscillating streaming potential between two electrodes. In addition, the absolute number of charges can be determined by titration to zero potential with a $10^{-5}-10^{-4} \mathrm{~mol} \mathrm{~L}^{-1}$ solution of oppositely charged polyelectrolyte particles of anionic poly-vinyl sulfate (PVS) or cationic poly-diallyl dimethyl ammonium chloride (PDADMAC).

\subsection{AIDA immersion mode freezing experiments}

To investigate the immersion mode ice nucleation efficiency of hematite particles, we conducted a series of controlled expansion cooling experiments using the AIDA cloud simulation chamber. Detailed experimental procedures of the immersion mode AIDA runs are described elsewhere (e.g., Steinke et al., 2011; Niemand et al., 2012), and only a con- cise discussion is provided here. The AIDA chamber consists of an $84 \mathrm{~m}^{3}$ aluminum vessel in a thermally insulated housing and is outfitted with instruments for heterogeneous ice nucleation studies of a wide variety of aerosols (e.g., Möhler et al., 2003, 2006; Mangold et al., 2005). Continuous cooling is simulated within the vessel by mechanically pumping and expanding the air in the vessel. During a typical expansion, constant pumping speed results in cooling rates decreasing from initially about $5^{\circ} \mathrm{C} \mathrm{min}^{-1}$ to below $0.1^{\circ} \mathrm{C} \mathrm{min}^{-1}$ while the chamber pressure reduces from $1000 \mathrm{mb}$ to $800 \mathrm{mb}$. Part of the chamber wall is coated with an ice layer, maintaining almost ice saturated conditions in the stirred chamber before the start of the pumping expansion. Thus, water supersaturation conditions occur shortly after pumping expansion begins, which is directly accessible from in situ tunable diode laser (TDL) water vapor absorption and gas temperature measurements. As soon as water saturation is exceeded, presumably the majority of the aerosol particles in the chamber acts as cloud condensation nuclei in our experiments and, therefore, become immersed into water droplets. From that point on, immersion mode ice nucleation of specific aerosol particles can be measured solely as a function of the temperature along with water saturation line (Connolly et al., 2009). An in situ scattering intensity measurement for the optical detection of ice was also conducted by the SIMONE (i.e., German acronym for Streulicht-Intensitätsmessungen zum optischen Nachweis von Eispartikeln) throughout the experiments. The instrument-performance and technical details are described in Schnaiter et al. (2012). Briefly, a horizontally aligned continuous wave semiconductor laser is used to probe light scattering of particles at the center location of the AIDA at a wavelength of $488 \mathrm{~nm}$. By changing the scattering plane at the laser head, scattering signals either in forward or backward direction can be detected. At the backward direction, scattering intensities perpendicular and parallel to the linear polarization state are evaluated and counted per second. At droplet- or ice-activation in the AIDA, a quick response in the intensities is observed. Further, an apparent increase in depolarization ratio (the ratio of those two intensities i.e., perpendicular/parallel) is a direct indicator of the appearance of nonspherical components and their contribution to enhanced light scattering. Hence, the precise timing for the formation of aspherical ice crystals can be recognized based on the depolarization ratio, and the simulated cloud phase (pure ice, mix phase, or liquid phase) in the AIDA is quantitatively identified. For our study, a depolarization ratio below 0.05 denoted the presence of unactivated aerosols (Fig. S1). During expansion cooling, the WhitE-Light Aerosol Spectrometer (WELAS) and optical particle counters (PALAS, Sensor series 2300 and 2500) were operated at a vertical sampling tube from the AIDA vessel in order to measure the number and size distribution of ice crystals. The WELAS instrument has been routinely used in previous studies at the AIDA facility, and a full description of the WELAS probe is available in Benz et al. (2005). 
Two types of the AIDA experiments were performed. First, we examined the immersion mode freezing of cubic hematite particles. These cubic hematite particles were injected into the AIDA cloud chamber by the Small-Scale Powder Disperser (SSPD, TSI, Model 3433), and homogeneously distributed by a mechanical fan deployed on the bottom of the AIDA vessel. Directly followed by the measurement of aerosol size distribution with an Aerosol Particle Sizer (APS, TSI, Model 3321), the expansion measurement was carried out in a temperature range of $-38^{\circ} \mathrm{C}<T<-28^{\circ} \mathrm{C}$, and ice onset was recorded. Next, for the second set of experiments, we injected milled hematite particles into the AIDA chamber by the Fluidized Bed Aerosol Generator (FBAG, TSI, Model 3400A). Accordingly, the series of expansion experiments were conducted in the same temperature range to assess the immersion mode nucleation efficiency of the milled particle subset. We note that the AIDA chamber was usually cleaned completely after each expansion experiment and then refilled with dry synthetic air to $1000 \mathrm{mb}$ for the following experiment. An exception to this was one expansion for the milled subset (INUIT02_54). For this particular expansion experiment, the immersion ice onset was evaluated for the leftover milled hematite particles from a previous expansion due to the dominance of deposition mode freezing during the first expansion. Fortunately, dominant immersion mode freezing was observed and recorded in the second subsequent experiment.

Afterwards, the ice nucleation ability was quantified as the ice nucleation active surface site (INAS) density, $n_{\mathrm{s}}\left(\mathrm{m}^{-2}\right)$, representing the number concentration of ice crystals $\left(N_{\text {ice }}\right.$; $\left.\mathrm{cm}^{-3}\right)$ normalized to the total surface area of aerosol ( $A_{\text {total }}$; $\mathrm{m}^{2} \mathrm{~cm}^{-3}$ ) as a function of temperature (e.g., Hoose and Möhler, 2012; Niemand et al., 2012). One caveat is that a uniform distribution of active sites over the given particle surface area is assumed, since there has been no direct measurement of ice nucleation at a particular site on the particle surface. Our $A_{\text {total }}$ was derived from the direct size distribution measurements of the aerosol in the AIDA chamber measured by an APS prior to the expansion experiment, or from offline BET measurement, $A_{\text {total,BET }}$. More specifically on the former one, the aerodynamic diameter of the APS was converted to a volume equivalent diameter assuming a unit slip correction factor and using a dynamic shape factor of 1.0 for cubic hematite particles and 1.2 for milled hematite particles in order to calculate the geometric total surface area, $A_{\text {total,geo }}$ (Peters et al., 2006). To obtain the latter one, the geometric total mass concentration $\left(M_{\text {total,geo }}\right.$; $\mathrm{g} \mathrm{cm}^{-3}$ ) is multiplied by BET specific surface (i.e., $\left.n_{\mathrm{s}, \mathrm{BET}}=N_{\text {ice }} /\left(M_{\text {total, geo }} \times S_{\mathrm{BET}}\right)=N_{\text {ice }} / A_{\text {total, BET }}\right)$. Thus, we obtained two different INAS densities, namely geometric area-based $n_{\text {s,geo }}$ (i.e., $N_{\text {ice }} / A_{\text {total,geo }}$ ) and BET-inferred $n_{\mathrm{s}, \mathrm{BET}}$ (i.e., $N_{\text {ice }} / A_{\text {total, BET }}$ ).

\subsection{Model and simulation}

For the modeling study, we used the single-column mode of the CAM5 model (Neale et al., 2010) to examine the sensitivity of simulated ice crystal number to the two aforementioned types of hematites as ice nucleating particles. One advantage of using a single-column model is that the performance of the physical parameterizations at a certain column over $100 \mathrm{~km}$ horizontal length scales can be evaluated in isolation from other columns. To drive the single-column model, ECMWF (i.e., acronym for European Centre for Medium Range Forecasts) analyses were used to derive the large-scale forcing terms, including vertical profiles of the horizontal advective tendencies of atmospheric state variables as well as the largescale vertical velocity (Zhang et al., 2001). The model consists of 30 vertical layers and the time step is set to $10 \mathrm{~min}$. The cloud case observed from the United States Department of Energy's Atmospheric Radiation Measurement facility located at the Southern Great Plain (SGP) site near Lamont, Oklahoma was chosen to test INAS parameterizations. The simulation was performed for the period from 29 March to 1 May 2010. Only model outputs in April are included in the analysis. In a pair of two idealized simulations, cubic and milled hematite particle concentrations are prescribed as $200 \mathrm{~L}^{-1}$, which is the average dust concentration simulated by the CAM5 model over SGP in springtime. The size and surface area of both types of hematite particles are prescribed with the mean surface area of hematite particles, which is equivalent to having the mean particle diameter of $1 \mu \mathrm{m}$ based on the spherical assumption. The ice nucleation rate is derived from experimentally determined INAS densities as a function temperature (see Eqs. 1-3) and is only applied in the limited temperature range $\left(-35.2^{\circ} \mathrm{C}<T<-33.5^{\circ} \mathrm{C}\right)$ for mixed-phase clouds. We also limited droplet freezing in our simulations below the mass mixing ratio of $10^{-8} \mathrm{~kg}$-cloud liquid per kg-air. In order to separate the impact of hematite from that of other ice nucleating aerosols, we switched off all other ice formation mechanisms: in situ homogenous and heterogeneous ice nucleation in pure ice phase clouds, heterogeneous freezing of natural dust particles, and cloud detrainment from shallow and deep convection.

\section{Results and discussions}

\subsection{Aerosol characterization}

Prior to each AIDA experiment, hematite particle samples were directly collected from the AIDA chamber on a $47 \mathrm{~mm}$ Nuclepore ${ }^{\circledR}$ substrate (Whatman, $0.2 \mu \mathrm{m}$ pore size filter 111106). Particles were then imaged by scanning electron microscopy (SEM, FEI, Quanta 650 FEG) to assess the general coverage of particles on the substrate and their overall visual appearance. Representative images of cubic and milled hematite particles are shown in Fig. 1a and b, respectively. 
A total of 1169 and 234 cubic and milled hematite particles were analyzed, respectively, by the scanning electron microscope, and particles were distributed according to their size and the bin width of $0.05 \mu \mathrm{m}$ diameter (Fig. 1c, d). An area equivalent diameter was calculated from the scanning electron microscope's projected area with an assumption of cubic shape. Scanning electron microscope images showed agglomerates of milled and cubic hematite particles. Analysis of these images was carried out, and we observed that milled particles are more prone to agglomeration than cubic particles, presumably due to regranulation of milled, small pieces. Nevertheless, chemical homogeneity within single particles was confirmed by energy dispersive X-ray (EDX) spectroscopy composition analysis, and EDX spectra of cubic and milled hematite particles were statistically similar at the $90 \%$ confidence limit (not shown here). The degree of surface irregularities as a result of milling was further confirmed by APS measurements that showed enhanced number concentrations of small particles in the AIDA chamber prior to the expansion experiment (Fig. 1e, f). The geometric total surface areas, $A_{\text {total,geo }}$, in the range of volume equivalent diameters from 0.2 to $9.6 \mu \mathrm{m}$ for particular experiments were determined as $578.2 \mu \mathrm{m}^{2} \mathrm{~cm}^{-3}$ (cubic) and $143.0 \mu \mathrm{m}^{2} \mathrm{~cm}^{-3}$ (milled), resulting in a total surface area concentration ratio of $\sim 4.0$. In addition, we compared these total surface area measurements to other offline measurements using the BET method and DLS. The measured BET surface areas $\left(S_{\mathrm{BET}}\right)$ are $2.2 \mathrm{~m}^{2} \mathrm{~g}^{-1}$ and $3.7 \mathrm{~m}^{2} \mathrm{~g}^{-1}$ for cubic and milled particles, respectively. Higher specific surface per unit mass of milled hematite particles are related to the increase of freshly exposed surface, edges and perhaps localized defects (e.g., cracks and steps). We note that the BET surface accounts for localized topography and is typically larger than simplified spherical estimation, resulting in a lower value of INAS density if employed (Hoose and Möhler, 2012). The surface area concentration ratio of cubic to milled hydrodynamic particle size per given mass $\left(\sim 10 \mathrm{mg} \mathrm{mL}^{-1}\right)$ as obtained by the DLS analysis was 3.9 (Fig. 1g, h), which is in a good agreement with in situ measurements from the AIDA chamber, thus validating the milled state of hematite particles.

Figure 2 shows the comparison of interfacial potentials as a function of $\mathrm{pH}$ for milled and cubic hematite obtained with the Brønsted-Lowry reaction. The charge potential of milled hematite particles is maximized at $\mathrm{pH} 2.4(427 \mathrm{mV})$, which is relatively high compared to the maximum potential of cubic hematite particles $(257 \mathrm{mV}$ at $\mathrm{pH} 2.8)$. We note that further acid titration beyond these maxima of potentials resulted in an abrupt decrease in potential due to the elevated potential compensation by free ions. Absolute number of charges were measured by polyelectrolyte titrations with PVS and PDADMAC. The detailed formulation and parameters used to calculate charge densities are reported in Table S1 of the Supplement. From that measurement, we also observed higher charge densities of the milled hematite particles (max. negative $=3.13 \pm 0.05 \mathrm{~nm}^{-2}$ and max. positive $=0.52 \pm 0.05 \mathrm{~nm}^{-2}$ ) than that of cubic hematite ones (max. negative $=1.39 \pm 0.03 \mathrm{~nm}^{-2}$ and max. positive $=0.36 \pm 0.03 \mathrm{~nm}^{-2}$ ), verifying relatively high charge potential of the milled particles. It is noteworthy that high storage capacity of charges due to protonated and deprotonated hydroxyl groups $(\mathrm{Fe}-\mathrm{OH})$ and oxo-groups ( $\mathrm{Fe}-\mathrm{O}-\mathrm{Fe})$ of iron oxide surface has been previously found by others, and the typical charge density of $\mathrm{Fe}-\mathrm{OH}$ of a metal oxide surface has been reported as $2-10 \mathrm{~nm}^{-2}$ (Di Cosimo et al., 1998; Schindler and Stumm, 1987).

Another feature in Fig. 2 is that the isoelectric point (i.e., the $\mathrm{pH}$ at which the particle surface carries zero charge potential) of milled hematite particles shifted towards a slightly higher $\mathrm{pH}$ when compared to cubic hematite particles. This implies that the surface of milled hematite particles is more basic than that of cubic ones, probably due to the presence of a relatively higher fraction of the basic groups (i.e., Fe-O$\mathrm{Fe}$ ) and/or due to a change in the coordinative environment of the functional groups and their enhanced chemical activity at surface kinks and edges (Schindler and Stumm, 1987). To conclude, a distinct difference in the surface chemical properties of milled and cubic hematite particles was found and ice might have nucleated at the active sites, which may coincide with a higher charge density on milled hematite particles (Mazeina and Navrotsky, 2007). These results may support previous molecular dynamic simulations such as in Croteau et al. (2010). A more quantitative analysis is required to relate surface chemical and physical properties of atmospherically relevant dust (e.g., natural dust) to ice nucleation activity.

\subsection{Influence of surface morphology from AIDA experiments}

The results of a total of four expansion cooling experiments are presented and interpreted in the context of contribution of surface irregularities. Two sets of AIDA experiments were analyzed, including two expansions for each cubic and milled hematite particles. Figure 3 summarizes all four AIDA experiments and illustrates the effect of surface irregularities by milling on ice nucleation properties expressed in INAS density. We observed the immersion mode ice nucleation activity, $n_{\mathrm{s}, \mathrm{geo}}$, of hematite to be dependent on temperature; i.e., $n_{\mathrm{s}, \mathrm{geo}}$ increases with decreases in temperature as previously observed (e.g., Steinke et al., 2011; Niemand et al., 2012). We note that $n_{\mathrm{s}, \text { geo }}$ of hematite is generally about two orders of magnitude smaller than that of natural dusts (Niemand et al., 2012). We also observed that, as postulated in Möhler et al. (2006), the milling process significantly enhances the overall ability of ice nucleation by more than an order of magnitude at $-35^{\circ} \mathrm{C}$. The observed differences may be attributed to the role of various surface features as a result of milling, such as higher charge density associated with the presence of different functional groups on the milled surface, or increased active site densities due to newly exposed 


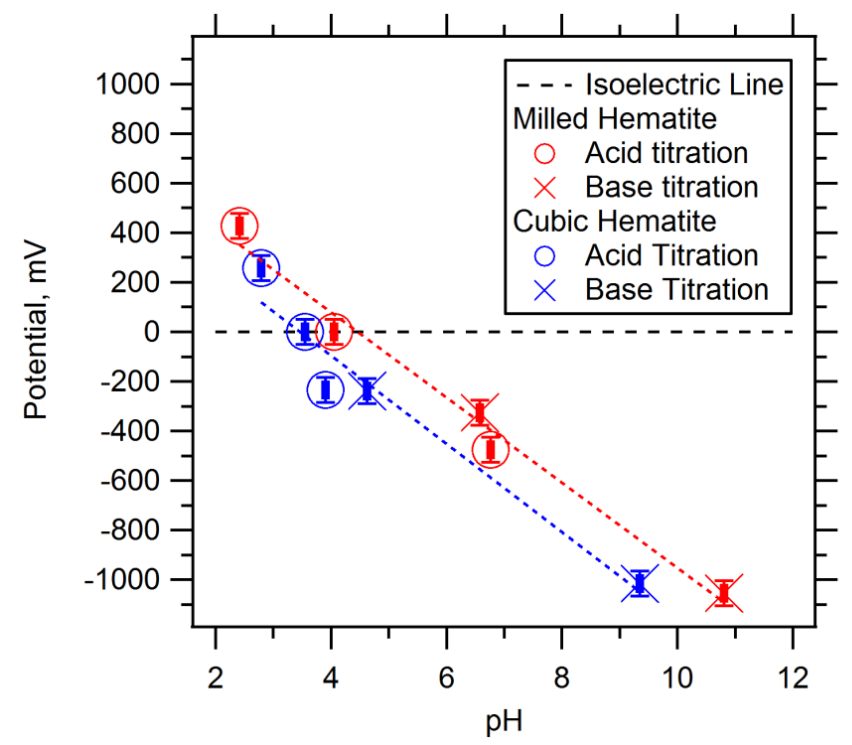

Fig. 2. Generation of charged particles by acid-base titration. Isoelectric line (black dashed) represents the $\mathrm{pH}$, at which hematite particle surfaces show zero charge potential. The colored dashed lines represent fits for each hematite particle subset. Error bars represent our experimental uncertainties \pm 0.05 for the $\mathrm{pH}$ values and $\pm 50 \mathrm{mV}$ for the potential.

surface and edges, or a combination of the two. Furthermore, both $n_{\mathrm{s} \text {, geo }}$ and $n_{\mathrm{s} \text {, BET }}$ are substantially higher for the milled hematite particles when compared to the cubic ones (Fig. 3). It is noteworthy that we did not examine the influence of one characteristic individually while keeping the other surface properties constant. Nevertheless, milled hematite has the same crystal structure as cubic hematite and, thus, our data show that a simple mechanical modification can increase $n_{\mathrm{s}, \text { geo }}$ by an order magnitude.

We note that a quantitatively small contribution of early deposition mode ice nucleation (i.e., ice formation due to the direct deposition of water vapor) before the full water droplet activation at $-33.5^{\circ} \mathrm{C}$ is routinely observed for both cubic and milled subsets (Fig. S1). For clarity, the contributions of deposition mode ice crystals (up to $27 \%$ of total ice crystals formed in an expansion) were excluded from the INAS density estimation. We also limit our analyses to the temperature range of heterogeneous ice nucleation and the measurement period where the ice probes were operated above their minimum detection limit. Hence, the contributions from homogeneous ice nucleation observed below $-35^{\circ} \mathrm{C}$ (Figs. S1, S2) and the time interval coinciding with measured ice crystal concentration below the WELAS detection limit $\left(<0.1 \mathrm{~cm}^{-3}\right)$ were excluded. Thus, we evaluated the droplet-freezing efficiency of hematite particles within the limited temperature range of $-35.2^{\circ} \mathrm{C}<T<-33.5^{\circ} \mathrm{C}$.

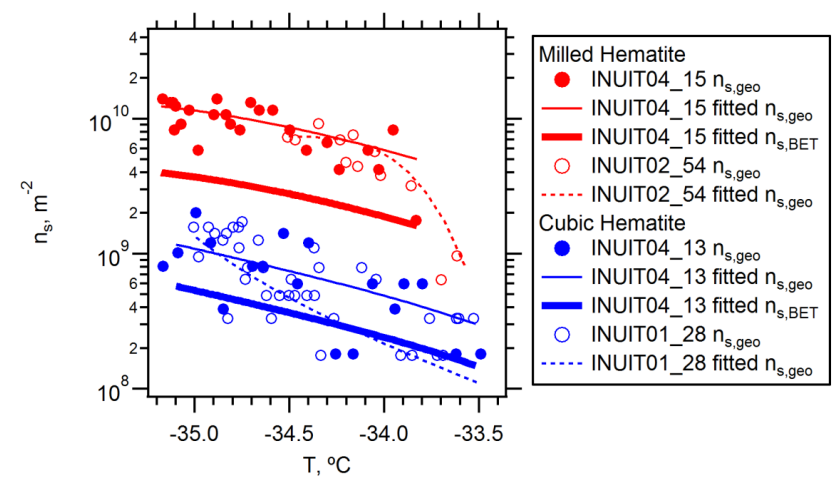

Fig. 3. INAS densities, geometric area-based $n_{\mathrm{s}}$, geo and BETinferred $n_{\mathrm{s}, \mathrm{BET}}$, for immersion freezing of cubic and milled hematite particles as a function of temperature, $T$. The thin solid lines correspond to fitted $n_{\mathrm{s} \text {, geo }}$ of INUIT04_15 and INUIT04_13 and the thin dashed lines correspond to fitted $n_{\text {s, geo }}$ of INUIT02_54 and INUIT01_28. The bold solid lines represent the BET-inferred $n_{\mathrm{S}, \mathrm{BET}}$ of INUIT04_15 and INUIT04_13. Note that experimental uncertainties are $T \pm 0.3{ }^{\circ} \mathrm{C}$ and $n_{\mathrm{S}} \pm 35 \%$ (Steinke et al., 2011).

\subsection{Influence of surface morphology from modeling perspective}

Figure 4 shows the simulated time evaluation of ice crystal number concentration and ice water content. Likewise, the simulated monthly mean vertical profiles over the same region are shown in Fig. 5. The ice nucleation rates used in our modeling simulations $\left(j_{\text {het }}^{\mathrm{c}}\right.$ for cubic hematite particles and $j_{\text {het }}^{\mathrm{m}}$ for milled ones; $\mathrm{s}^{-1}$ ) are derived from experimentally determined temperature-dependent geometric area-based INAS densities as

$$
\begin{aligned}
{\left[\begin{array}{c}
j_{\text {het }}^{\mathrm{c}}(T) \\
j_{\text {het }}^{\mathrm{m}}(T)
\end{array}\right] } & =\left[\begin{array}{c}
n_{\mathrm{s}, \mathrm{ceo}}^{\mathrm{c}}(T) \\
n_{\mathrm{s}, \mathrm{geo}}^{m}(T)
\end{array}\right] \times A_{\text {mean }} / \Delta t, \\
n_{\mathrm{s}, \text { geo }}^{\mathrm{c}}(T) & =1.072 \times 10^{8}+1.777 \times 10^{-6} \\
& \times \exp (-0.969 \times T),
\end{aligned}
$$

$$
\begin{aligned}
n_{\mathrm{s}, \mathrm{geo}}^{\mathrm{m}}(T) & =2.523 \times 10^{9}+2.605 \times 10^{-4} \\
& \times \exp (-0.889 \times T),
\end{aligned}
$$

where $T$ is the temperature $\left({ }^{\circ} \mathrm{C}\right), n_{\mathrm{s}, \text { geo }}^{\mathrm{c}}(T)$ is the geometric area-based INAS density of cubic hematite particles $\left(\mathrm{m}^{-2}\right), n_{\mathrm{s}, \mathrm{geo}}^{\mathrm{m}}(T)$ is the geometric area-based INAS density of milled hematite particles $\left(\mathrm{m}^{-2}\right), A_{\text {mean }}$ is the mean surface area of a single hematite particle $\left(\sim 3.1 \times 10^{-12} \mathrm{~m}^{2}\right)$, and $\Delta t$ is the evaluated time step. Ice nucleation induced by hematite particles appears mostly at around $400 \mathrm{hPa}$, because it can only happen in the limited temperature range $-35.2^{\circ} \mathrm{C}<T<-33.5^{\circ} \mathrm{C}$. Ice number predicted in the cubic hematite case varies from less than one per liter to a few per 

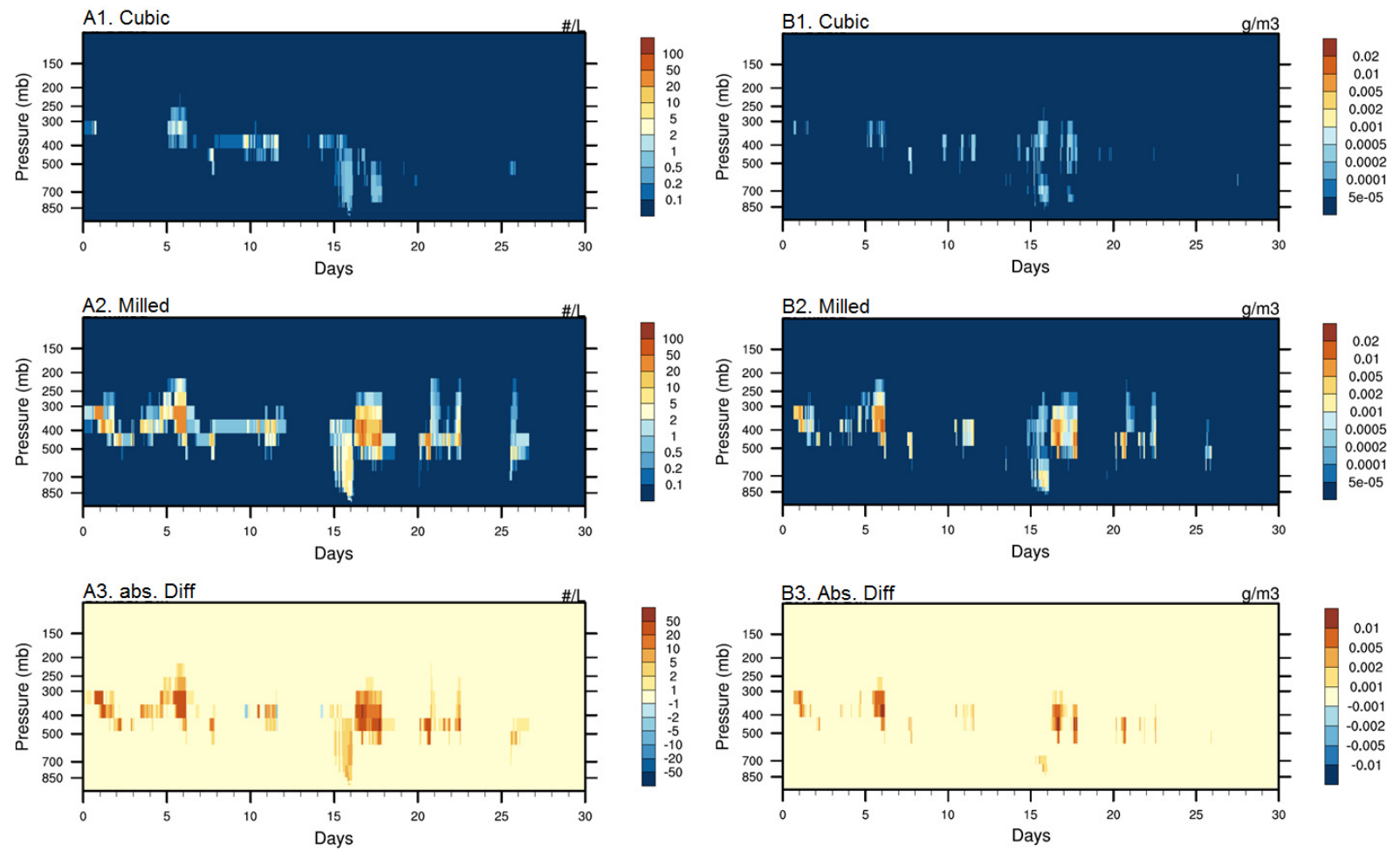

Fig. 4. Simulated time evolution of (A) ice crystal number concentration (color scaled; $\mathrm{L}^{-1}$ ) and (B) mass mixing ratio of cloud ice (color scaled; $\mathrm{g} \mathrm{m}^{-3}$ ) over the ARM-SGP site in April 2010. Top panel shows the result of a simulation with cubic hematite particles and middle panel shows that of the milled hematite particles. Bottom panel shows the absolute difference between these two simulations.

liter. During most of the time, the milled hematite case predicts much higher ice number concentrations than the cubic case, due to its higher INAS density, owing probably from surface morphology (edges, cracks and steps) or charging state. Due to the convective transport and sedimentation processes, ice crystals can be redistributed higher than $250 \mathrm{hPa}$ and lower than $700 \mathrm{hPa}$ before they evaporate or convert to snow. Between $200 \mathrm{hPa}$ and $500 \mathrm{hPa}$, the simulated ice number for the milled hematite case is on average one order of magnitude higher than for the cubic hematite particles. As a result, the ice water path increases significantly in the milled hematite case (Figs. 4b, 5b). It should be noted that in these idealized model simulations we intentionally switched off all other ice formation processes, so the simulated ice number concentrations are not realistic and cannot be compared to observations. We also note that the model application in this study only demonstrates the effect of using different INAS densities for a given aerosol population on the ice crystal number concentration. Nevertheless, the sensitivity shown in Fig. 4 indicates that the change of nucleation rate due to the properties of the surface in the milled particles is fully confirmed, and can further lead to significant changes of ice cloud formation process in the upper troposphere. Apart from ice nucleation, our model simulations consider complex ice microphysical processes as well as temporal evolution of mass and number densities of four hydrometeor classes (i.e., cloud droplets, ice crystals, raindrops and snow). Our results show that even though the ice nucleation efficiency differs only in a small temperature range for the two types of hematite particles, it has an important impact on the simulated ice number and mass concentrations from $200 \mathrm{hPa}$ to $700 \mathrm{hPa}$. Hence, the response of the model to the change in ice nucleation efficiency was successfully demonstrated. For future analyses, we suggest a modeling study examining the effect of milling or other characteristic surface morphology on the ice nucleation efficiency of atmospherically relevant clay mineral particles (e.g., illite, kaolinite, and feldspar) and comparison of simulated INAS densities to the AIDA measurements with ground powder samples.

\section{Conclusions}

Laboratory and modeling studies were performed to examine the role of surface morphology upon ice nucleation on hematite particles that heterogeneously freeze at $-35.2^{\circ} \mathrm{C}<T<-33.5^{\circ} \mathrm{C}$. Two different forms of laboratorygenerated hematite particles were used in this study. Milled hematite particles were generated by mechanically agitating $1 \mu \mathrm{m}$ diameter cubic hematite particles with $100 \mu \mathrm{m}$ diameter bronze beads, and its immersion mode ice onset was first quantitatively measured using the AIDA cloud simulation 

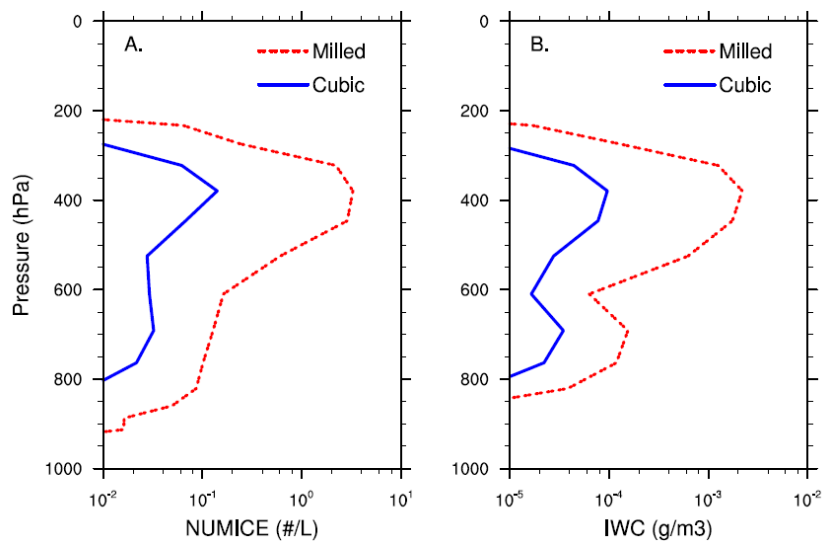

Fig. 5. Simulated monthly mean vertical profile of (A) ice crystal number concentration $\left(\mathrm{L}^{-1}\right)$ and $(\mathbf{B})$ ice water content $\left(\mathrm{g} \mathrm{m}^{-3}\right)$ over the ARM-SGP site in April 2010.

chamber at the temperature below $-28^{\circ} \mathrm{C}$. An isometric experiment was conducted on cubic hematite particles. The observed ice nucleation activity of milled hematite particles inferred by the INAS density, either related to the geometric or the BET-derived specific surface area, was up to an order of magnitude higher than that of the original cubic hematite particles. Thus, the characteristics of the surface as a result of milling appear to have a substantial effect on the immersion mode ice nucleation efficiency.

We also estimated the interfacial potential independently. Interestingly, our charge-pH titration measurements showed a qualitative but reasonable (about a factor of two) difference in surface chemistry. For instance, the milled hematite particles contained more chemically active functional groups that can store charges and exhibited higher charge potential than the original cubic hematite particles. This difference may contribute to form stable multiple layers of water molecules at the surface and may enhance freezing at these sites. This observation may also imply that the active sites (e.g., localized surface features such as cracks and edges) of morphologically complex aerosols may have plausible and quantitative relevance to heterogeneous freezing mechanisms in the atmosphere, but also in laboratory experiments.

Additionally, the results from the laboratory experiments were adapted in the computationally efficient version of the CAM5 model to simulate ice crystal number concentration in cirrus clouds during April 2010 at the SGP site. We performed a set of simulations that include one with INAS densities for cubic hematite particles and another with INAS densities for milled hematite particles. The ice nucleation in both cases is considered as heterogeneous droplet freezing in mixed-phase clouds (i.e., only happens when cloud droplets exist). The comparison of these two simulations suggested that the surface irregularities and associated active sites lead to greater ice activation through droplet freezing.
Overall, the influence of surface morphology of hematite particles upon the ice nucleation efficiency was verified by an experimental study, and the influence of enhanced ice nucleation activity was demonstrated by a modeling approach. We note that the conclusions from the current study are limited to the idealized droplet freezing of known composition and size, and a quantitative analysis for a wide range of different particle types and experimental conditions are required for a complete understanding of the relative importance of active sites over aerosol size and chemistry. The modeling studies beyond the single-column analysis presented in this study, specifically estimating corresponding longwave cloud forcings, are needed to examine the influence of active sites on overall heterogeneous ice-nucleating properties, which constrain the aerosol-cloud interactions and cloud model parameterizations.

\section{Supplementary material related to this article is available online at http://www.atmos-chem-phys.net/14/ 2315/2014/acp-14-2315-2014-supplement.pdf.}

Acknowledgements. The authors gratefully acknowledge financial support provided by the German Research Society (DfG) under contracts MO668/4-1 and KO2944/2-1 within FOR 1525 INUIT. G. Kulkarni and K. Zhang acknowledge support from the Department of Energy Atmospheric System Research Program and thank J. Fast for providing an opportunity to integrate measurements into the model. K. Zhang thanks X. Liu for his help on the model setup and S. Xie for providing the atmospheric forcing data used in this study. We thank the AIDA technicians, R. Buschbacher, T. Chudy, E. Kranz, G. Scheurig, and S. Vogt, for their continuous and dedicated support for the operation of AIDA. Technical support from M. Schnaiter for the SIMONE measurements and data processing is appreciated. The expertise of T. Kisely for the BET measurements is gratefully acknowledged. We thank P. Weidler and S. Jaeger for the preparation of the hematite particles. We also thank P. Alpert and D. Knopf for useful discussions. The Pacific Northwest National Laboratory is operated for DOE by Battelle Memorial Institute under contract DE-AC05-76RLO 1830.

We acknowledge support by Deutsche Forschungsgemeinschaft and the Open Access Publishing Fund of the Karlsruhe Institute of Technology.

The service charges for this open access publication have been covered by a Research Centre of the Helmholtz Association.

Edited by: A. Bertram 


\section{References}

Anim-Danso, E., Zhang, Y., Alizadeh, A., and Dhinojwala, A.: Freezing of water next to solid surfaces probed by infraredvisible sum frequency generation spectroscopy, J. Am. Chem. Soc., 135, 2734-2740, 2013.

Benz, S., Megahed, K., Möhler, O., Saathoff, H., Wagner, R., and Schurath, U.: T-dependent rate measurements of homogeneous ice nucleation in cloud droplets using a large atmospheric simulation chamber, J. Photoch. Photobio. A, 176, 208-217, 2005.

Biver, M. and Shotyk, W.: Stibiconite $\left(\mathrm{Sb}_{3} \mathrm{O}_{6} \mathrm{OH}\right)$, senarmontite $\left(\mathrm{Sb}_{2} \mathrm{O}_{3}\right)$ and valentinite $\left(\mathrm{Sb}_{2} \mathrm{O}_{3}\right)$ : Dissolution rates at $\mathrm{pH} 2-11$ and isoelectric points, Geochim. Cosmochim. Ac., 109, 268-279, 2013.

Brunauer, S., Emmett, P. H., and Teller, E.: Adsorption of gases in multimolecular layers, J. Am. Chem. Soc., 60, 309-319, 1938.

Connolly, P. J., Möhler, O., Field, P. R., Saathoff, H., Burgess, R., Choularton, T., and Gallagher, M.: Studies of heterogeneous freezing by three different desert dust samples, Atmos. Chem. Phys., 9, 2805-2824, doi:10.5194/acp-9-2805-2009, 2009.

Croteau, T., Bertram, A. K., and Patey, G. N.: Water adsorption on kaolinite surfaces containing trenches, J. Phys. Chem. A, 114, 2171-2178, 2010.

Cziczo, D. J., Froyd, K. D., Hoose, C., Jensen, E. J., Diao, M., Zondlo, M. A., Smith, J. B., Twohy, C. H., and Murphy, D. M.: Clarifying the dominant sources and mechanisms of cirrus cloud formation, Science, 340, 1320-1324, doi:10.1126/science.1234145, 2013.

Di Cosimo, J. I., Díez, V. K., Xu, M., Iglesia, E., and Apesteguía, C. R.: Structure and surface and catalytic properties of $\mathrm{Mg}$-Al basic oxides, J. Catal., 178, 499-510, 1998.

Ehre, D., Lavert, E., Lahav, M., and Lubomirsky, I.: Water freezes differently on positively and negatively charged surfaces of pyroelectric materials, Science, 327, 672-675, 2010.

Gavish, M., Wang, J. L., Eisenstein, M., Lahav, M., and Leiserowitz, L.: The role of crystal polarity in alpha-amino acid crystals for induced nucleation of ice, Science, 256, 815-818, 1992.

Gaware, V. S., Håkerud, M., Leósson, K., Jónsdóttir, S., Høgset, A., Berg, K., and Másson, M.: Tetraphenylporphyrin tethered chitosan based carriers for photochemical transfection, J. Med. Chem., 56, 807-819, 2013.

Hiranuma, N., Brooks, S. D., Moffet, R., Glen, A., Laskin, A., Gilles, M. K., Liu, P., MacDonald, M. A., Strapp, W., and McFarquhar, G. M.: Chemical characterization of individual particles and residuals of cloud droplets and ice crystals collected on board research aircraft in the ISDAC 2008 study, J. Geophys. Res.-Atmos., 118, 6564-6579, doi:10.1002/jgrd.50484, 2013.

Hoose, C. and Möhler, O.: Heterogeneous ice nucleation on atmospheric aerosols: a review of results from laboratory experiments, Atmos. Chem. Phys., 12, 9817-9854, doi:10.5194/acp-12-98172012, 2012.

Jacquemain, D., Leveiller, F., Weinbach, S. P., Lahav, M., Leiserowitz, L., Kjaer, K., and Als-Nielsen, J.: Crystal structure of self-aggregates of insoluble aliphatic amphiphilic molecules at the air-water interface. An x-ray synchrotron study, J. Am. Chem. Soc., 113, 7684-7691, 1991.

Kulkarni, G. and Dobbie, S.: Ice nucleation properties of mineral dust particles: determination of onset $\mathrm{RH}_{i}$, IN active fraction, nucleation time-lag, and the effect of active sites on contact angles,
Atmos. Chem. Phys., 10, 95-105, doi:10.5194/acp-10-95-2010, 2010.

Linke, C., Möhler, O., Veres, A., Mohácsi, Á., Bozóki, Z., Szabó, G., and Schnaiter, M.: Optical properties and mineralogical composition of different Saharan mineral dust samples: a laboratory study, Atmos. Chem. Phys., 6, 3315-3323, doi:10.5194/acp-63315-2006, 2006.

Lohmann, U. and Feichter, J.: Global indirect aerosol effects: a review, Atmos. Chem. Phys., 5, 715-737, doi:10.5194/acp-5-7152005, 2005.

Mangold, A., Wagner, R., Saathoff, H., Schurath, U., Giesemann, C., Ebert, V., Krämer, M., and Möhler, O.: Experimental investigation of ice nucleation by different types of aerosols in the aerosol chamber AIDA: implications to microphysics of cirrus clouds, Meteorol. Z., 14, 485-497, 2005.

Mason, B. J.: The Physics of Clouds, Oxford University Press, London, England, 688 pp., 1971.

Mazeina, L. and Navrotsky, A.: Enthalpy of water adsorption and surface enthalpy of goethite $(\alpha-\mathrm{FeOOH})$ and hematite $(\alpha$ $\mathrm{Fe}_{2} \mathrm{O}_{3}$ ), Chem. Mater., 19, 825-833, 2007.

Möhler, O., Stetzer, O., Schaefers, S., Linke, C., Schnaiter, M., Tiede, R., Saathoff, H., Krämer, M., Mangold, A., Budz, P., Zink, P., Schreiner, J., Mauersberger, K., Haag, W., Kärcher, B., and Schurath, U.: Experimental investigation of homogeneous freezing of sulphuric acid particles in the aerosol chamber AIDA, Atmos. Chem. Phys., 3, 211-223, doi:10.5194/acp-3-211-2003, 2003.

Möhler, O., Field, P. R., Connolly, P., Benz, S., Saathoff, H., Schnaiter, M., Wagner, R., Cotton, R., Krämer, M., Mangold, A., and Heymsfield, A. J.: Efficiency of the deposition mode ice nucleation on mineral dust particles, Atmos. Chem. Phys., 6, 30073021, doi:10.5194/acp-6-3007-2006, 2006.

Neale, R. B., Chen, C.-C., Gettelman , A., Lauritzen, P. H., Park, S., Williamson, D. L., Conley, A. J., Garcia, R., Kinnison, D., Lamarque, J.-F., Marsh, D., Mills, M., Smith, A. K., Tilmes, S., Vitt, F., Morrison, H., Cameron-Smith, P., Collins, W. D., Iacono, M. J., Easter, R. C., Ghan, S. J., Liu, X., Rasch, P. J., and Taylor, M. A.: Description of the NCAR Community Atmosphere Model (CAM5.0), Tech. Rep. NCAR/TN-486-STR, NCAR, available at: http://www.cesm.ucar.edu/models/cesm1.0/ cam/ (last access: 8 January 2013), 2010.

Niemand, M., Möhler, O., Vogel, B., Vogel, H., Hoose, C., Connolly, P., Klein, H., Bingemer, H., Skrotzki, J., and Leisner, T.: A particle-surface-area-based parameterization of immersion freezing on mineral dust particles, J. Atmos. Sci., 69, 3077-3092, 2012.

Peters, T. M., Ott, D., and O'Shaughnessy, P. T.: Comparison of the Grimm 1.108 and 1.109 portable aerosol spectrometer to the TSI 3321 aerodynamic particle sizer for dry particles, Ann. Occup. Hyg., 50, 843-850, 2006.

Pruppacher, H. R. and Klett, J. D.: Microphysics of Clouds and Precipitation, Atmospheric and Oceanographic Sciences Library, Kluwer Academic Publishers, Dordrecht, the Netherlands, 309360, 1997.

Schill, G. P. and Tolbert, M. A.: Heterogeneous ice nucleation on phase-separated organic-sulfate particles: effect of liquid vs. glassy coatings, Atmos. Chem. Phys., 13, 4681-4695, doi:10.5194/acp-13-4681-2013, 2013. 
Schindler, P. W. and Stumm, W.: The Surface Chemistry of Oxides; Hydroxides, and Oxide Minerals in Aquatic Surface Chemistry: Chemical Processes at the Particle-Water Interface John Wiley and Sons, New York, 83-110, 1987.

Schnaiter, M., Büttner, S., Möhler, O., Skrotzki, J., Vragel, M., and Wagner, R.: Influence of particle size and shape on the backscattering linear depolarisation ratio of small ice crystals - cloud chamber measurements in the context of contrail and cirrus microphysics, Atmos. Chem. Phys., 12, 10465-10484, doi:10.5194/acp-12-10465-2012, 2012.

Shilling, J. E., King, S. M., Mochida, M., Worsnop, D. R., and Martin, S. T.: Mass spectral evidence that small changes in composition caused by oxidative aging processes alter aerosol $\mathrm{CCN}$ properties, J. Phys. Chem. A, 111, 3358-3368, 2007.

Steinke, I., Möhler, O., Kiselev, A., Niemand, M., Saathoff, H., Schnaiter, M., Skrotzki, J., Hoose, C., and Leisner, T.: Ice nucleation properties of fine ash particles from the Eyjafjallajökull eruption in April 2010, Atmos. Chem. Phys., 11, 12945-12958, doi:10.5194/acp-11-12945-2011, 2011.
Sugimoto, T. and Sakata, K.: Preparation of monodisperse pseudocubic $\alpha-\mathrm{Fe}_{2} \mathrm{O}_{3}$ particles from condensed ferric hydroxide gel, J. Colloid Interf. Sci., 152, 587-590, 1992.

Titze, J., Christian, M., Jacob, F., Parlar, H., and Ilberg, V.: The possibilities of particle analysis demonstrated by the measurement of the colloidal stability of filtered beer, J. Inst. Brew., 116, 405-412, 2010.

Twohy, C. H. and Anderson, J. R.: Droplet nuclei in nonprecipitating clouds: composition and size matter, Environ. Res. Lett., 3, 045002, doi:10.1088/1748-9326/3/4/045002, 2008.

Ukhatskaya, E. V., Kurkov, S. V., Matthews, S. E., and Loftsson, T.: Antifungal drug solubilizing activity and self-aggregation ability of cationic aminocalix [4] arene in comparison to SBEbCD: effect of addition of water-soluble polymer, J. Incl. Phenom. Macro., doi:10.1007/s10847-013-0302-5, 2013.

Zhang, M. H., Lin, J. L., Cederwall, R., Yio, J., and Xie, S. C.: Objective analysis of ARM IOP data: method, features, and sensitivity, Mon. Weather Rev., 129, 295-311, 2001. 